\title{
Aplicação do SIG em estudos de degradação ambiental: o caso de São Carlos (SP)
}

\author{
Nívea Adriana Dias Pons ${ }^{1} \&$ Osni José Pejon ${ }^{2}$
}

\begin{abstract}
Resumo Este trabalho apresenta a proposta de uma técnica para levantamento e diagnóstico geológico-geotécnico de áreas degradadas e em processo de degradação em ambientes urbanos, utilizando-se como ferramenta o geoprocessamento. A área de estudo é a cidade de São Carlos - SP (área urbana e de expansão). Os dados apresentados foram obtidos de trabalhos realizados anteriormente e com o uso de geoprocessamento, técnicas de fotointerpretação e mapeamento geotécnico. As informações do meio físico já existentes e as informações produzidas foram integradas e representadas no Sistema de Informações Geográficas (Spring 4.2 - Câmara et al. 1996), associado ao banco de dados. As ferramentas disponibilizadas pelo Spring 4.2 permitiram sobrepor os diferentes atributos inseridos em tabelas e nos documentos cartográficos e, com isso, agilizaram as análises e promoveram conclusões mais precisas a respeito do meio físico da cidade de São Carlos. O estudo permitiu identificar que a maioria das degradações encontradas na cidade foram causadas pela ocupação inadequada que não considerou as condições ambientais existentes, resultando em danos ao meio físico e, consequentemente, à qualidade de vida da população urbana.
\end{abstract}

Palavras-chave: áreas degradadas, SIG, mapeamento geotécnico, ocupação urbana.

\begin{abstract}
Use of geographic information system in studies of environmental degradation: the case of the city São Carlos (SP). This work presents a methodology of engineering geological survey of land degradation in urban environments using geoprocessing tools. The studied area is São Carlos city, state of São Paulo (urban and expansion area). The data presented were obtained of early studies made, and through the use of geographical information system, photointerpretation, and engineering geological mapping. Both existing and produced environmental information were integrated and represented in the geographical information system (Spring 4.2), and associated to the data base. The tools contained in the Spring 4.2 allowed to overlay the different attributes inserted in tables and cartographic documents and speed up the analysis and promote conclusions with more accuracy about physical environment of São Carlos city. This study allowed to identify that the majority of the degradations found in the city were caused by the inadequate occupation that did not consider environment conditions, resulting in damages to the environment and, therefore, to the quality of life of the urban population.
\end{abstract}

Keywords: land degradation, GIS, engineering geological mapping, urban occupation.

INTRODUÇÃO No estudo da degradação ambiental é necessário conhecer as relações entre os elementos que constituem o meio natural, entender os processos, fenômenos e comportamentos do meio físico relacionados com as diferentes formas de interferência das ações humanas.

A classificação e avaliação da degradação ambiental é um dos maiores problemas de interesse no mundo. Muitos métodos têm sido propostos, entre eles, o geoprocessamento tem sido aplicado para identificar e caracterizar áreas degradadas e monitorar as tendências das degradações (Feng et al. 2005).

O geoprocessamento consiste no conjunto de tecnologias voltadas à coleta e tratamento de informações espaciais para um objetivo específico e envolve quatro categorias de técnicas relacionadas ao tratamento de informações espaciais (Rodrigues 1993): técnicas para coleta, armazenamento, tratamento, análise e uso integrado de informação espacial.

Este trabalho buscou desenvolver um procedi- mento para o levantamento e diagnóstico geológico-geotécnico de áreas degradadas e em processo de degradação na cidade de São Carlos-SP (área urbana e de expansão), utilizando como ferramenta o geoprocessamento.

Para isso foram integradas as informações do meio físico já existentes e as informações produzidas, as quais foram representadas em um SIG - Sistema de Informações Geográficas (Spring 4.2 - Câmara et al. 1996), associado ao banco de dados deste SIG.

ÁREA DE ESTUDO O Município de São Carlos está localizado na região central do Estado de São Paulo, entre as coordenadas $47^{\circ} 30^{\prime}$ e $48^{\circ} 15^{\prime}$ 'Longitude Oeste e $21^{\circ} 30^{\prime}$ e $22^{\circ} 15^{\prime}$ ' Latitude Sul, conforme mostrado na figura 1. A área ocupada pelo município é de 1.140,90 $\mathrm{km}^{2}$ (Oliveira 1996).

A área adotada para este estudo compreende $160,0 \mathrm{~km}^{2}$, a qual foi determinada em função das bacias hidrográficas existentes dentro ou próximo à área urba- 


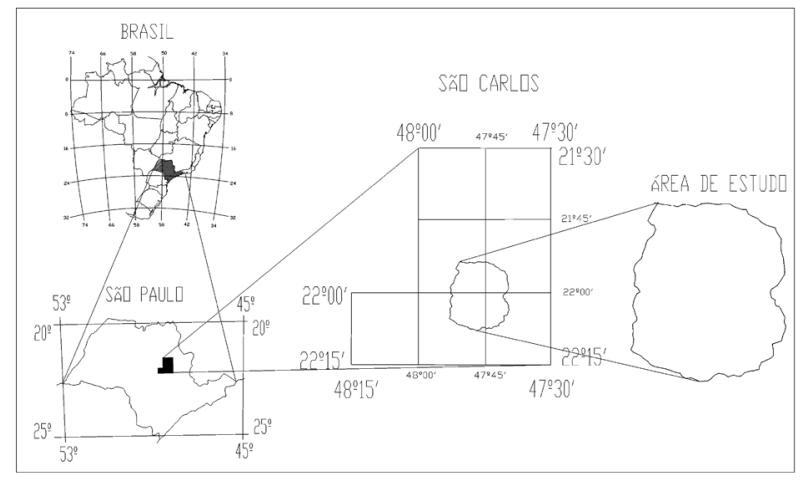

Figura 1- Localização da área de estudo.

nizada. Apesar da drenagem de algumas bacias ocorrer na direção contrária à área urbanizada, tornou-se necessário abrangê-las, tendo em vista a futura ocupação do local. Esta ocupação tanto pode ser residencial quanto industrial, sendo que a instalação desta última torna o estudo mais relevante ainda.

MÉTODOS Tendo em vista o objetivo da pesquisa que é realizar o levantamento e diagnóstico geológico-geotécnico das áreas degradadas na cidade de São
Carlos-SP, o plano de trabalho adotado baseou-se em trabalhos de campo e laboratório, considerou a proposta metodológica para o desenvolvimento da cartografia geotécnica de Zuquette (1987), e utilizou o geoprocessamento como ferramenta para integrar e analisar as informações produzidas. A figura 2 apresenta o fluxograma das etapas executadas nesta pesquisa.

Em função da grande quantidade de informações compiladas e produzidas, tornou-se necessário organizá-las a fim de que as consultas, sobreposições e análises pudessem ser realizadas de forma rápida e precisa. Optou-se por utilizar o SIG Spring 4.2, o qual é capaz de importar e manipular os mapas e cartas produzidos, associar um ou mais sistemas de banco de dados a um ou mais documentos cartográficos.

Tratamento das informações no SIG Primeiramente, no Spring 4.2 foi criado o Banco de Dados e o projeto no sistema de projeção UTM, Datum horizontal Córrego Alegre, Meridiano central $45^{\circ} \mathrm{W}$ e fuso 23 .

Em seguida, os vetores dos documentos cartográficos foram exportados com a extensão dxf R12 e importados no Spring 4.2. Para cada tipo de informação foi criada uma categoria, conforme o modelo dos dados (Imagem, MNT, Temático, Objeto, Cadastral, Rede, Não-Espacial). Para os documentos inseridos no modelo temáti-

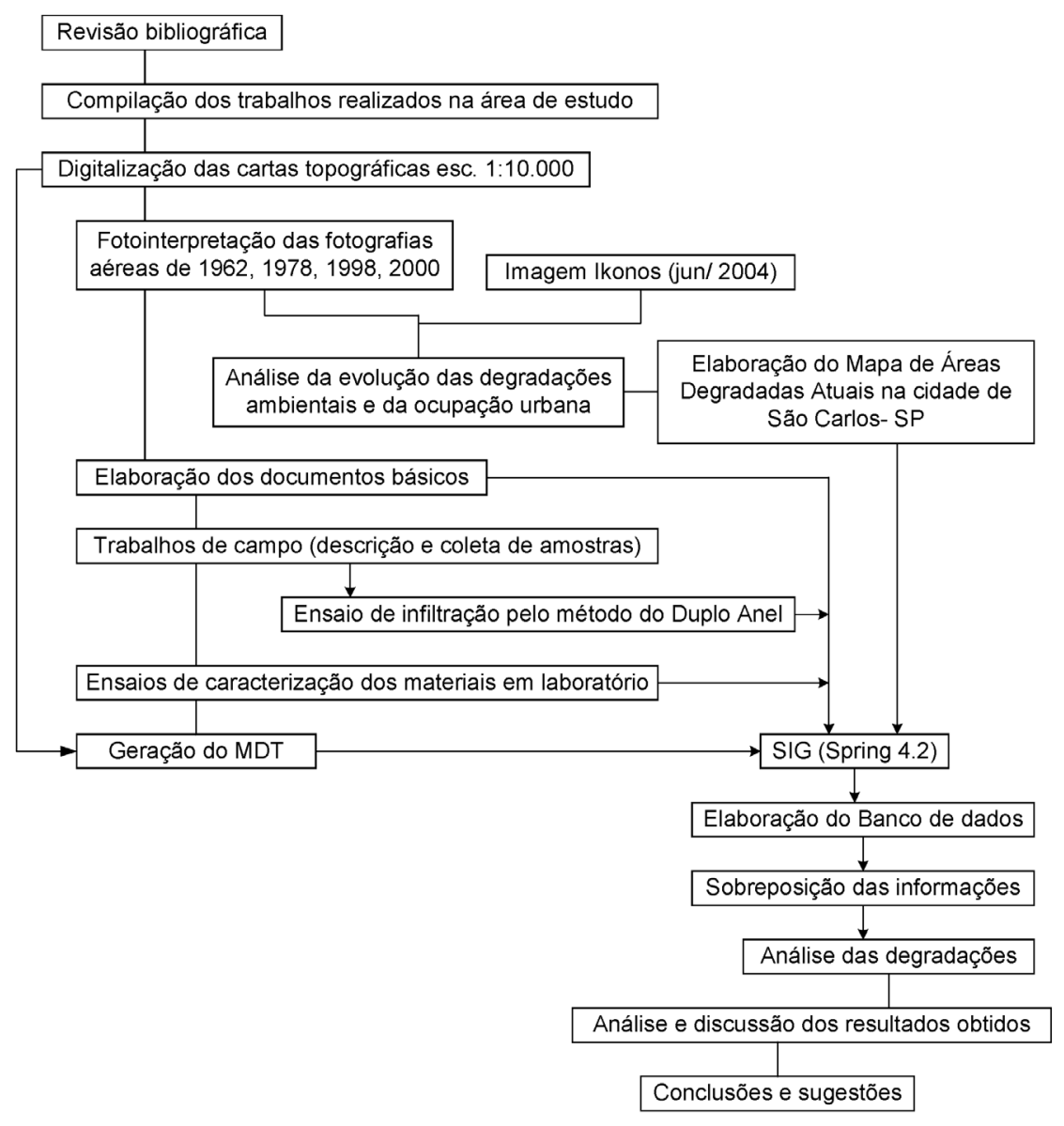

Figura 2 - Fluxograma das etapas executadas na pesquisa. 
co (Mapa de Materiais Inconsolidados, Mapa de Substrato Geológico) foram definidas as classes correspondentes, as quais foram associadas aos polígonos traçados.

O Mapa de Documentação foi inserido no modelo cadastral e foram criadas categorias objeto, correspondentes aos trabalhos realizados na área de estudo e às informações geradas neste trabalho. Desta forma, tornou-se possível criar as tabelas de consulta do banco de dados através da inserção das informações de cada ponto descrito, amostrado e/ou ensaiado.

A Carta de Localização das Áreas Degradadas Atuais foi inserida na categoria temática e teve seus polígonos classificados nas respectivas degradações. Também houve necessidade de criar a categoria cadastral para esta carta, com a finalidade de inserir as informações das planilhas de campo de cada degradação observada na cidade. Neste caso, foram criadas as categorias objeto de cada uma das degradações e associados os atributos definidos para as observações em campo.

A seguir, o banco de dados elaborado é apresentado de forma mais detalhada.

Sistemas de banco de dados associados às informações pontuais A construção do banco de dados dos registros pontuais referentes aos trabalhos compilados e também gerados neste estudo envolveu o desenvolvimento de oito tabelas. Estas tabelas estão no formato DBF e fazem parte do sistema de banco de dados do Spring 4.2.

As tabelas contêm os atributos referentes aos resultados dos ensaios de determinação dos índices físicos (umidade (w), índice de vazios (e), massa específica do solo $(\rho)$, massa específica dos sólidos ( $\rho s)$, massa específica seca $(\rho d)$, CTC, granulometria, textura, espessura, coloração) obtidos em trabalhos anteriores (Zuquette 1981, Aguiar 1989, Nishiyama 1989, Muro 2000) (134 pontos), resultados de sondagens SPT e IPT obtidos por Bortolucci (1983) (135 pontos), resultados de ensaios realizados no estudo de Pons (2006) em amostras indeformadas de materiais inconsolidados, ensaios de infiltração (15 pontos) e informações obtidas através de pontos visitados em campo (35 pontos).

As tabelas de pontos observados contêm as informações das planilhas de campo utilizadas nas visitas a cada degradação existente na cidade. A tabela das áreas degradadas por erosão contém os seguintes campos: situação atual, comprimento, largura, profundidade, tempo de existência, local de formação (drenagem ou encosta), obras executadas, vegetação, fluxo d'água, assoreamento, risco, perda da fertilidade do solo, perda da função econômica. A tabela das áreas degradadas por mineração contém os atributos referentes à situação atual, data da desativação (no caso da atividade ter sido desativada), plano de recuperação, visual, fluxo d'água, condições de estabilidade da escavação (grau de fraturamento, queda de blocos, inclinação de taludes), vegetação e rejeitos. Para as áreas degradadas por retirada de mata ciliar ou desmatamento de cabeceira de drenagem foi construída a tabela com os seguintes atributos: nome da drenagem, danos causados, tipo de ocupação atual.
Sistemas de banco de dados associados aos documentos cartográficos elaborados Os documentos cartográficos inseridos no banco de dados do Spring 4.2 na forma vetorial, com os seus polígonos associados ao banco de dados, foram os seguintes: Mapa de Materiais Inconsolidados, Mapa de Substrato Geológico e Mapa de Localização das Áreas Degradadas Atuais na Cidade de São Carlos- SP.

No Spring 4.2 existem duas formas de dispor as informações cartográficas ao usuário, conforme a necessidade: na categoria temático (onde são definidas as classes das informações e estas são associadas aos polígonos), ou na categoria cadastral (onde os polígonos são associados aos objetos pré-definidos).

Neste estudo, os Mapas de Materiais Inconsolidados e de Substrato Geológico foram inseridos na categoria temático, e a Carta de Localização das Áreas Degradadas Atuais foi inserida nas duas formas, como temático e cadastral. Na categoria temático, os polígonos foram associados às classes pré-determinadas referentes ao tipo de degradação. Na categoria cadastral, os polígonos foram associados aos objetos correspondentes ao tipo de erosão em que foram definidos os atributos referentes às planilhas de campo, já comentados anteriormente.

A Carta de Declividades foi elaborada no Spring 4.2 como forma de utilização da ferramenta do SIG. As curvas de nível digitalizadas foram inseridas no Spring 4.2, na categoria MNT (Modelo Numérico do Terreno), como amostras; foi gerada a grade TIN (Triangular Irregular Network- estrutura vetorial com topologia do tipo nó) e realizado o fatiamento, tendo sido as classes pré-definidas $(0-2 \%, 2-5 \%, 5-10 \%, 10-15 \%,>15 \%)$. Com o banco de dados elaborado no Spring 4.2 foi possível realizar diversas consultas, exemplificadas a seguir, as quais permitiram fazer as análises das degradações existentes na área de estudo.

\section{RESULTADOS E ANÁLISES}

Consultas realizadas utilizando o banco de dados e os documentos cartográficos O Sistema de banco de dados do Spring 4.2 permite fazer consultas de diferentes formas, de acordo com a necessidade do usuário, seja para obter informações pontuais ou de toda a área de trabalho.

Como exemplo, ao se consultar a tabela dos atributos com as informações da área degradada por erosão no Bairro Cidade Aracy, como mostrado na figura 3, além das informações das dimensões da área, estado atual da degradação e da vegetação, riscos existentes, grau de perda da fertilidade do solo e de perda da função econômica, também é possível visualizar a foto digital da área.

Os recursos de consulta a mapas cadastrais ou redes no Spring 4.2 permitem considerar os atributos descritivos dos objetos. Sendo assim, utilizou-se o conceito de coleção de objetos, que permite extrair da tabela de objetos somente aqueles de interesse para o usuário, criando uma tabela auxiliar. Como exemplo, tem-se na figura 4 uma consulta ao Plano de Informação (PI) erosão, em que foi gerada a coleção somente das áreas em que a boçoroca atingiu a profundidade das águas subterrâneas. A figura 4 


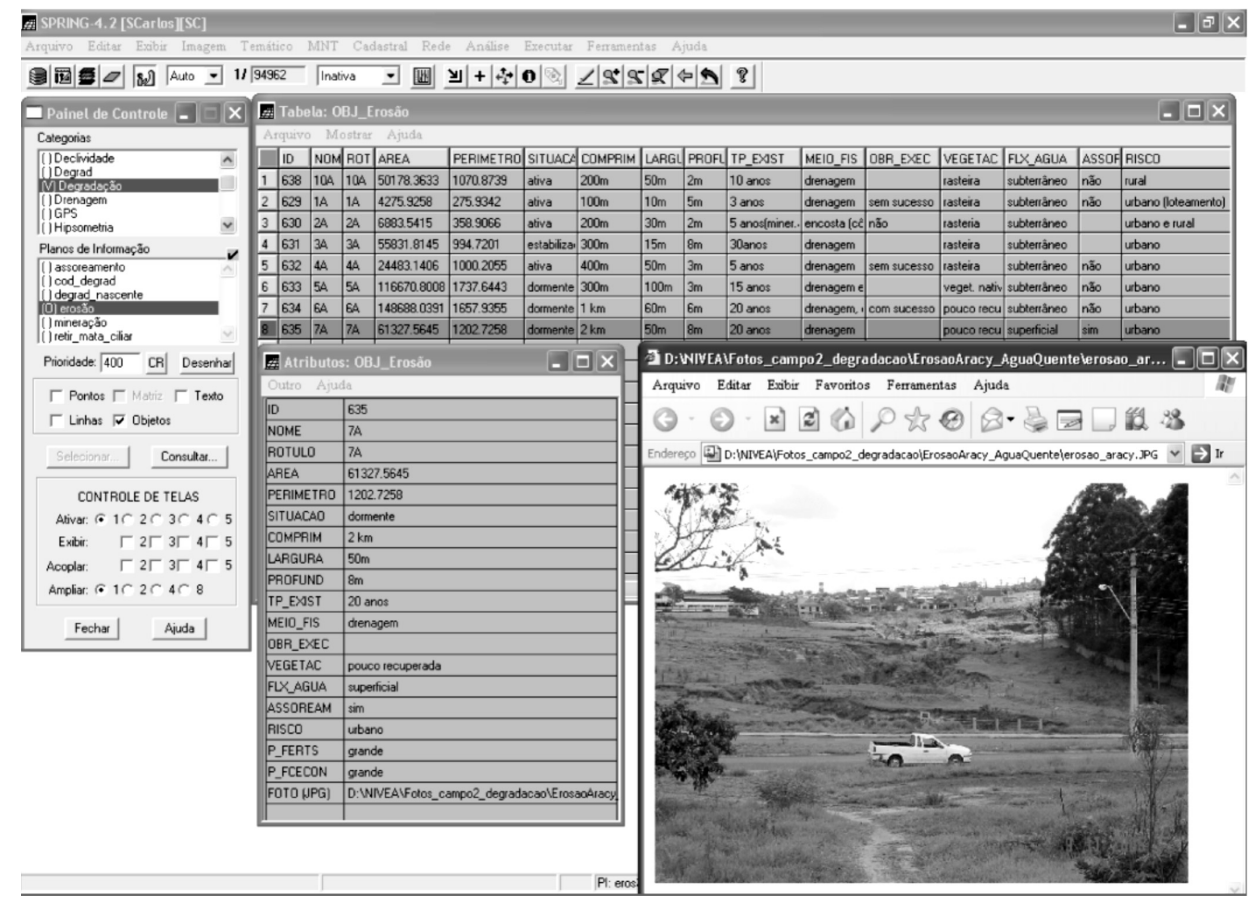

Figura 3 - Consulta ao Banco de dados do Spring 4.2 através da função consulta a objetos, visualização dos atributos e inserção de foto digital, através de módulo que permite associação de dados de multimídia.

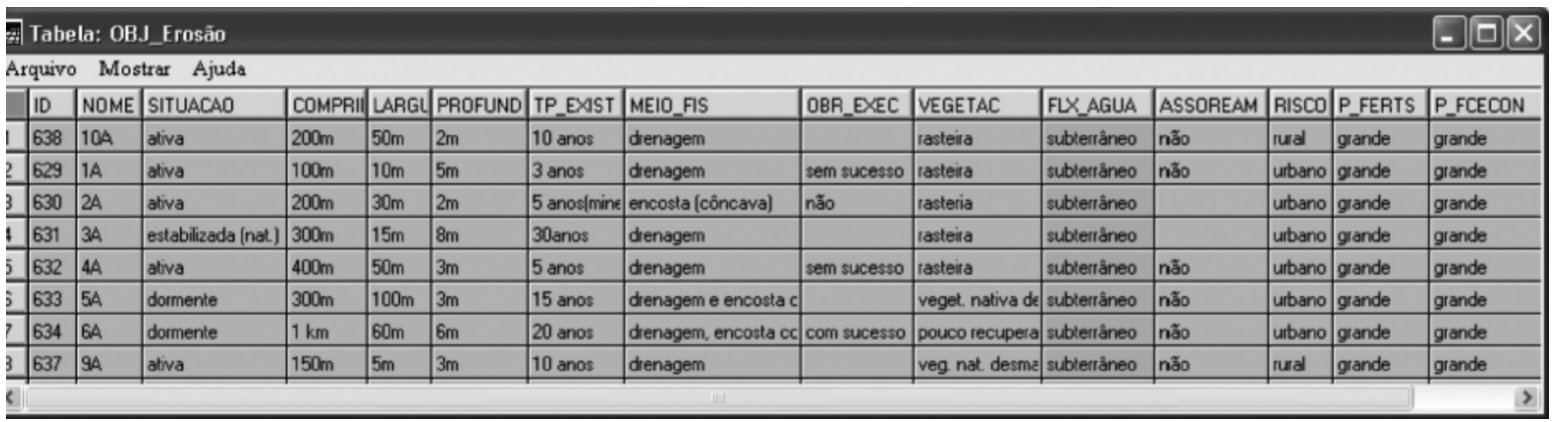

Figura 4 - Tabela contendo a coleção de objetos erosão com o atributo fluxo d'água (FLX_AGUA) subterrâneo agrupado.

mostra a tabela correspondente à coleção criada.

Também é possível gerar um PI de categoria Temática ou Cadastral a partir de um agrupamento ou consulta espacial realizada nos objetos georreferenciados. Uma vez realizado o agrupamento das erosões que atingiram o fluxo d'água subterrâneo, é possível materializar este procedimento em um outro PI. Na figura 5 é mostrada a criação do PI da categoria cadastral que contém as áreas degradadas por erosão selecionadas.

O SIG Spring 4.2 também permite gerar Mapas de distâncias que representam um tipo de análise de proximidade. Neste estudo foi gerado o mapa de distância para as drenagens da cidade, a fim de analisar o quanto a ocupação urbana se aproximou das áreas ribeirinhas $\mathrm{e}$ a interferência desse comportamento para o surgimento das degradações ambientais. Na figura 6 é mostrado o Mapa de distâncias gerado no Spring 4.2, cujas classes representam as faixas marginais de proteção ao longo de cursos d'água, definidas pelo Código Florestal - Lei $\mathrm{n}^{\circ}$ 7.803, de 18 de julho de 1989 (Brasil 2006): de 0 a $30 \mathrm{~m}$, de 30 a $50 \mathrm{~m}$, de 50 a $100 \mathrm{~m}$.

Nesta análise foi possível observar que a ocupação urbana não respeitou a faixa de proteção ao longo de vários cursos d'água. Como exemplo, observa-se na figura 7, a imagem Ikonos da região central da cidade de São Carlos, ao longo do Córrego Gregório, área mais crítica onde ocorrem inundações nas épocas de chuvas intensas. Na figura 8 , o buffer de 30 metros gerado é sobreposto a imagem Ikonos, mostrando a densidade de ocupação urbana e, conseqüentemente, de impermeabilização que ocorreu nas margens deste curso d'água.

O uso desta ferramenta tem grande importância, principalmente no caso de prevenir a retirada da mata ciliar em novas áreas devido à ocupação inade- 


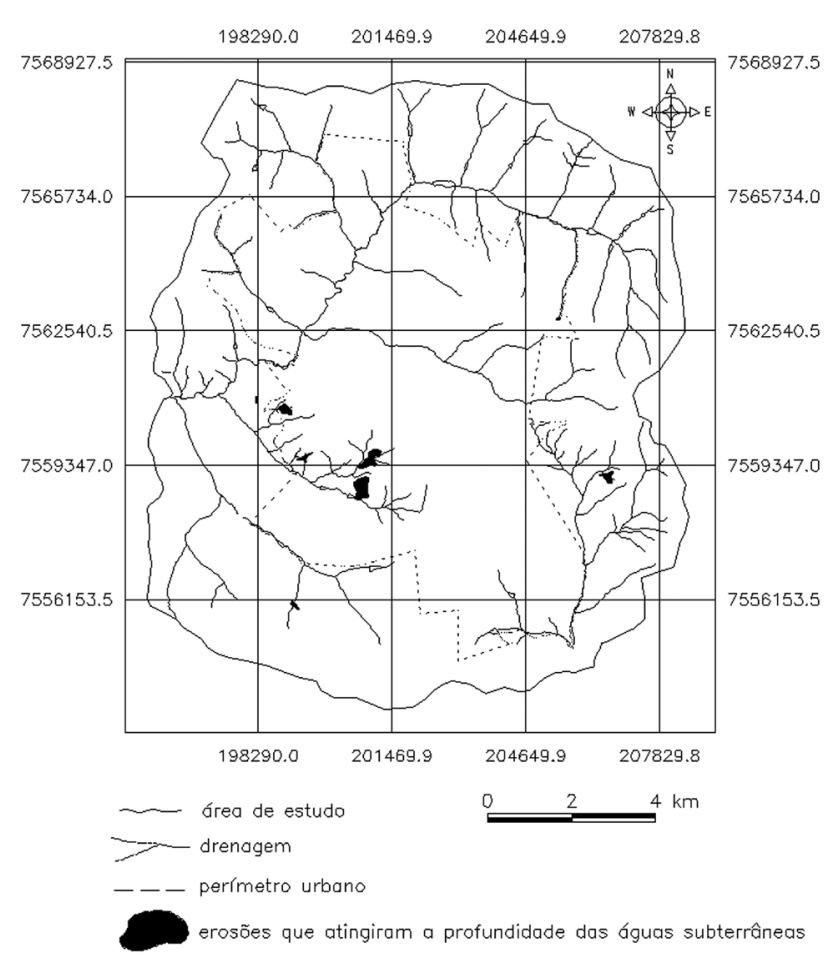

Figura 5 - Plano de Informação (PI) da categoria cadastral gerado a partir da tabela de coleção de objetos erosão com o atributo fluxo d'água subterrâneo.

Mapa de distâncias das drenagens na cidade de São Carlos (SP)

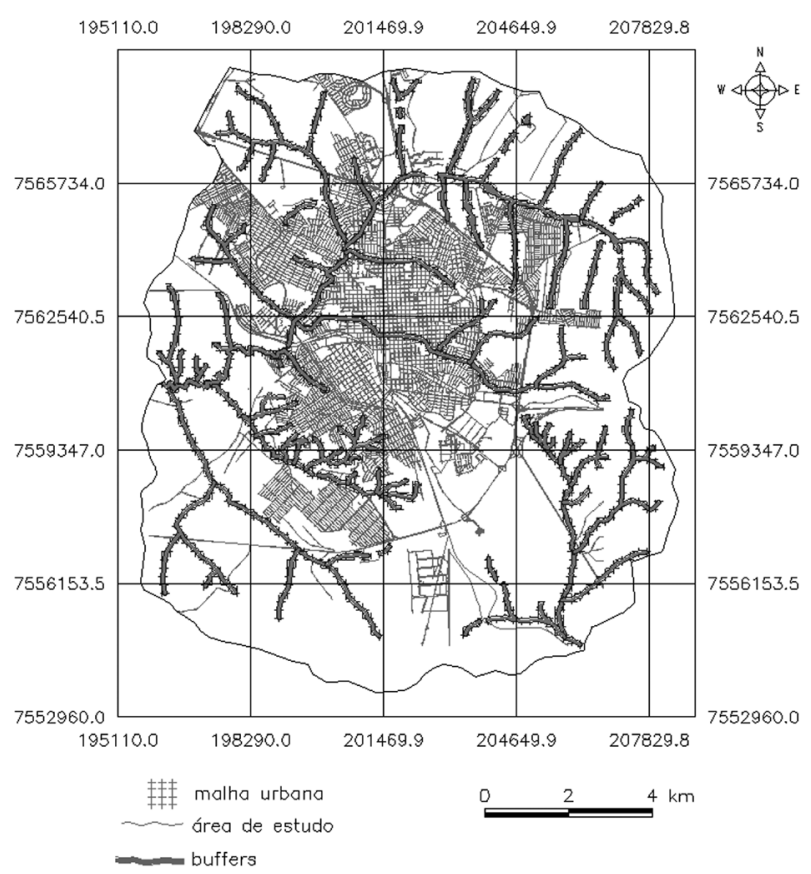

Figura 6 - Mapa de distâncias gerado no Spring 4.2 com os buffers que representam as faixas de proteção ao longo dos cursos d'água.

quada. Na figura 9 observa-se a área de cabeceira do Rio Monjolinho, onde um loteamento está sendo cons-

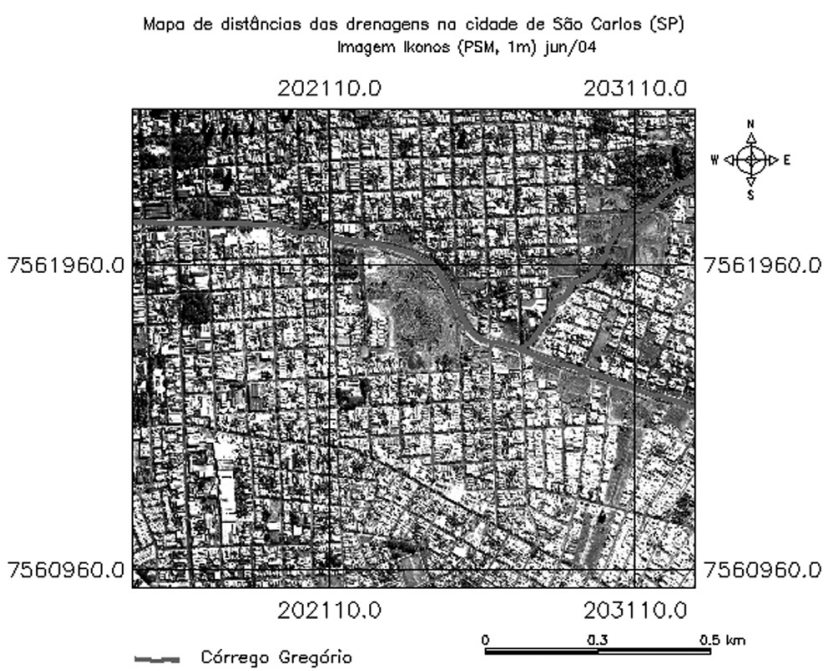

Figura 7 - Imagem Ikonos (Pons 2006) da região central da cidade de São Carlos, ao longo do Córrego Gregório, onde pode-se observar a elevada ocupação urbana, impermeabilização do solo e risco de inundações.

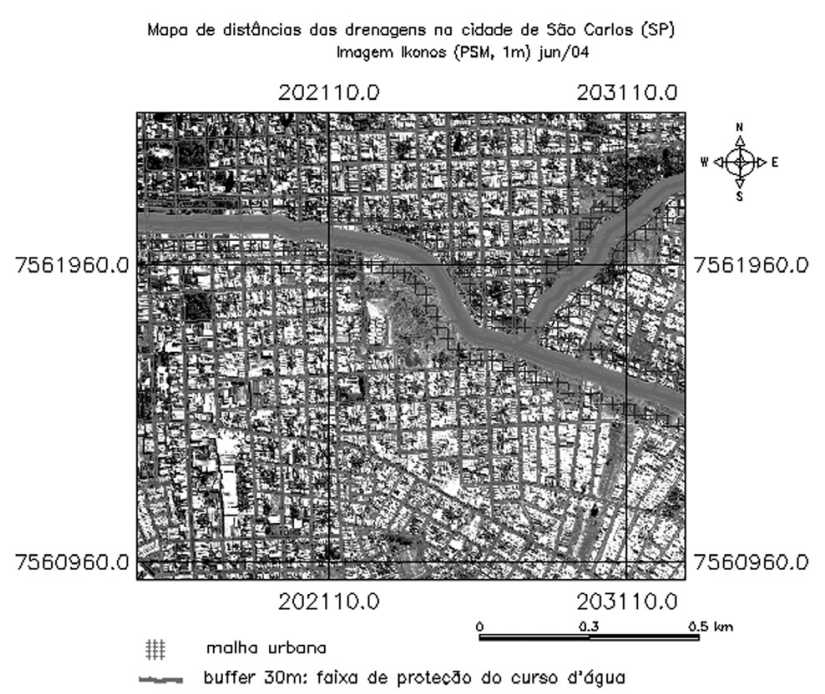

Figura 8 - Imagem Ikonos (Pons 2006) sobreposta pelo buffer igual a 30 metros do Mapa de distâncias ao longo do Córrego Gregório. A elevada ocupação urbana invadiu a faixa de proteção do curso d'água.

truído, apesar da legislação ambiental delimitar a área de proteção. Como conseqüência, observa-se o desmatamento da vegetação nativa e a formação de processos erosivos. Através da análise do Mapa de distâncias é possível monitorar áreas de risco de degradações e evitar impactos maiores ao meio físico.

Contribuições do SIG para o estudo das degradações ambientais As análises do meio físico realizadas no SIG Spring 4.2 tornaram-se rápidas devido à facilidade 
de sobreposição das informações cartográficas. Como já foi apresentado anteriormente, o Sistema de banco de dados do Spring 4.2 permite obter informações a respeito de cada ponto da área de estudo.

No caso da análise dos materiais inconsolidados e substrato geológico existente em cada polígono correspondente à determinada degradação, foi possível verificar e analisar os respectivos comportamentos, causas e conseqüências do local degradado. A figura 10 mostra esta análise e o resultado obtido para uma área degradada à leste do núcleo urbano, em área de nascentes. No ponto selecionado, observa-se a presença da Formação Botucatu e declividade maior que 15\%, o que justifica a fragilidade da área e destaca a importância da conservação do meio físico.

Na figura 11 pode-se observar, através da análise do banco de dados do Spring 4.2, que as áreas degradadas por erosão ocorrem em locais que apresentam as características de maior fragilidade, ou seja, áreas de nascentes de drenagens, altas declividades e presença da Formação Botucatu. O ponto selecionado para consulta simplificada na tela do Spring 4.2 apresentou o relatório de dados, que pode ser salvo no formato txt. Para esta consulta foi desenhado na tela do Spring a carta de declividades e as drenagens, sobrepostas ao mapa de substrato geológico e a carta de degradações.

As ferramentas disponibilizadas pelo Spring 4.2 permitiram sobrepor os diferentes atributos inseridos em tabelas e nos documentos cartográficos (caracterização do meio físico, ocupação urbana) e, com isso, agilizaram as análises e promoveram conclusões mais precisas a respeito do meio físico da cidade de São Carlos.

Além disso, também observou-se que o Sistema de banco de dados do Spring 4.2 permite que usuários menos especializados possam realizar as consultas de forma fácil e dinâmica e obtenham os resultados desejados.

Análise das degradações ambientais A análise das degradações ambientais levou em consideração dois fatores principais: características do meio físico (fragilidade natural, relevo, água, solo) e ação antrópica.

Com base nas consultas realizadas ao banco de dados do SIG Spring 4.2 foi possível observar que em determinadas degradações, o meio físico foi o fator condicionante, como no caso do assoreamento observado nas margens do Córrego Água Quente, próximo à cabeceira, à oeste da área urbana. Nesta região tem-se a presença do material Residual do Botucatu e declividades médias (5 a 10\%). Este material tem alta susceptibilidade às erosões e conseqüentemente, em função do desmatamento da área, ocorreram vários problemas de erosão e assoreamento. A mata ciliar nesta drenagem, observada em imagens mais antigas, não se apresentou muito densa em determinados trechos, desde essa época, sendo a vegetação arbustiva a mais encontrada, com raízes que alcançam menores profundidades. Isto leva a crer que o assoreamento verificado é influenciado pelas características naturais, porém foi agravado pela ocupação inadequada que ocorreu nos anos seguintes.

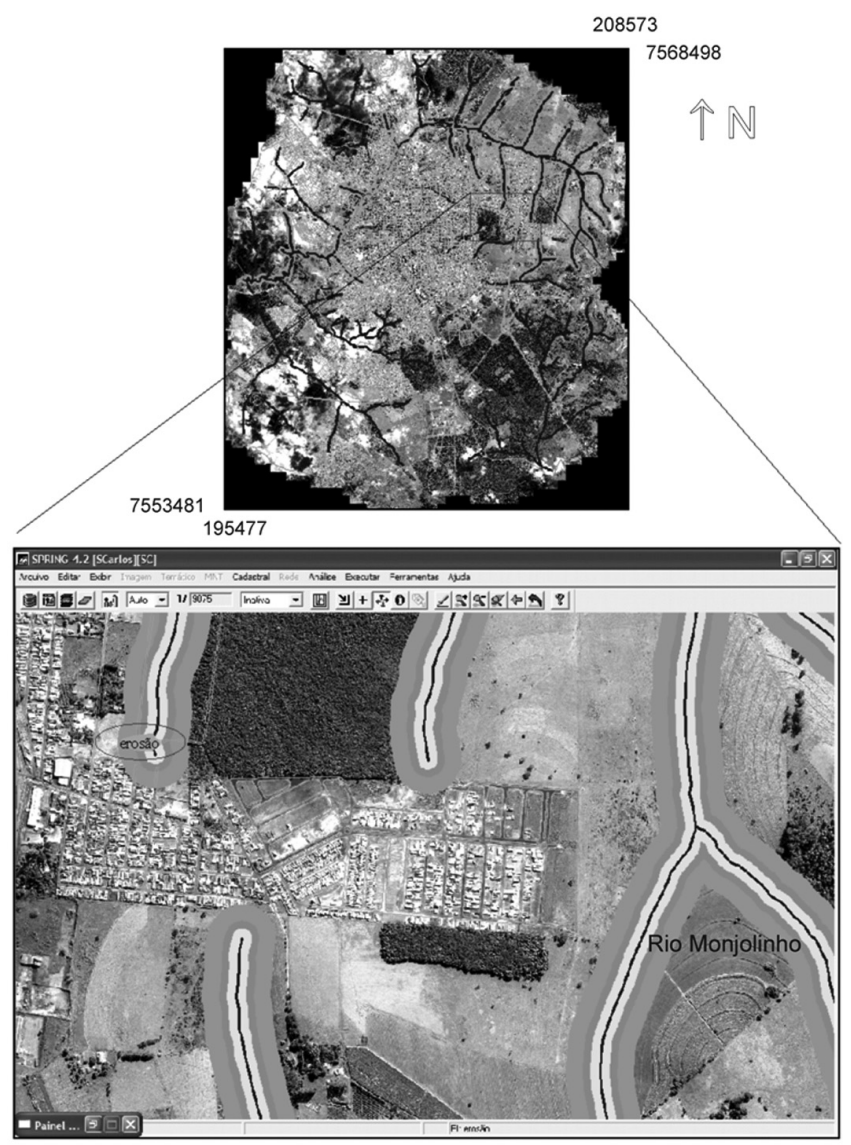

Figura 9 - Cabeceira do rio Monjolinho, onde a visualização da imagem Ikonos e do Mapa de distâncias permitem verificar que a ocupação urbana invadiu a faixa de proteção do curso d'água e ocasionou a degradação do meio fisico.

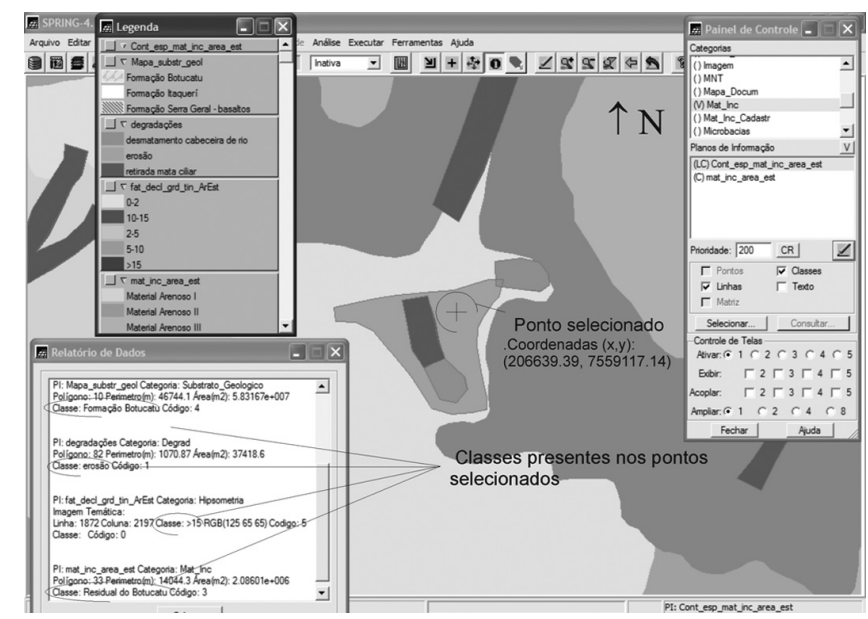

Figura 10 - Análise do meio físico existente no local onde ocorreu processo erosivo, utilizando o Spring 4.2. Os planos de informação ativos na tela referem-se à declividade, materiais inconsolidados, substrato geológico e degradação. 


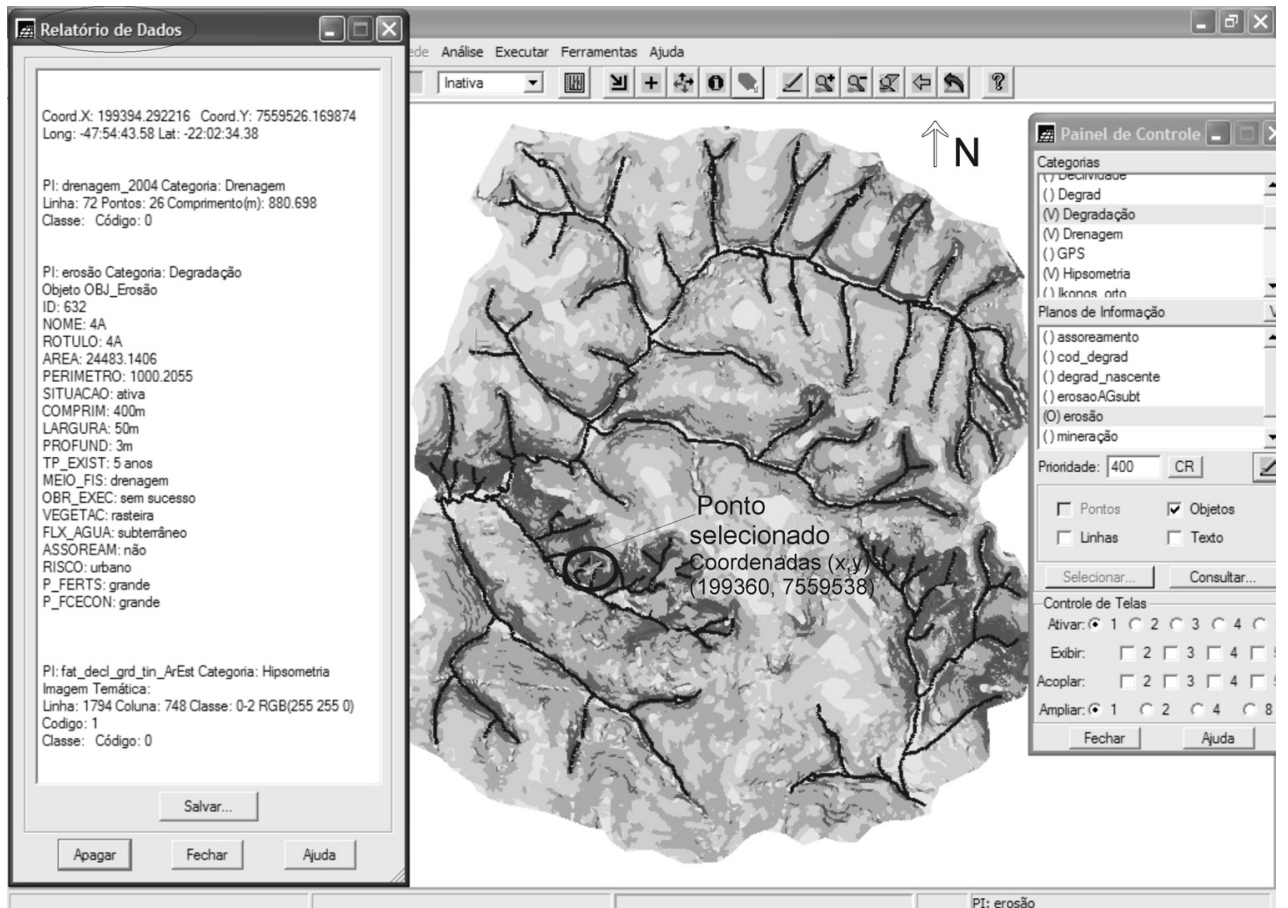

Figura 11 - Tela do Spring 4.2 (onde aparece desenhada a carta de declividades e as drenagens, sobrepostas ao mapa de substrato geológico, carta de degradações), cuja consulta simplificada gerou as informações comuns a todas as áreas degradadas por erosão: alta declividade, presença da Formação Botucatu, áreas de nascentes.

Isto fica claro em outros locais onde ocorreram processos erosivos muito mais intensos (Bairro Cidade Aracy), onde a fragilidade do meio físico associada à ocupação intensa e de forma inadequada foram os fatores indutores. A presença dos materiais arenosos em áreas de alta declividade e alterados pela ação antrópica formam um conjunto de fatores favoráveis à ocorrência de processos erosivos, demonstrando que estas áreas deveriam ter sido ocupadas com critérios rigorosos de proteção contra a erosão. Este aspecto serve de alerta para que nas demais áreas de ocorrência da Formação Botucatu, nas bacias dos Córregos Água Quente e Água Fria, ainda não urbanizadas, sejam tomadas medidas preventivas para evitar o aparecimento de novos problemas ou o agravamento dos já existentes.

Quanto às áreas de mineração abandonadas presentes na cidade, estas são consideradas áreas de risco para a população local e causam danos ao meio físico pela exposição dos materiais às intempéries.

A solução de aterro das áreas de mineração abandonadas, com resíduos inertes, torna-se atraente, pois ao mesmo tempo em que recompõe a topografia, eliminando as cavas profundas, também dá destinação a resíduos que ocupam extensas áreas quando não são lançados em qualquer terreno abandonado. No entanto, não há oferta de resíduos inertes suficiente para solucionar o problema das cavas em áreas de planície de inundação. Outra solução é a manutenção dos lagos, que podem servir para amortecer as cheias. Mas, com certeza, as soluções devem ser discutidas pelos órgãos ambientais, bem como a eficiência das soluções alternativas que estão sendo propostas atualmente.

Já as áreas de mineração ativas podem vir a ser consideradas de risco, devido ao encerramento das atividades e abandono do local. O plano de recuperação da área degradada (PRAD), que não seja apenas o isolamento do local para recuperação da vegetação, é necessário em função de que o meio físico alterado deve ser utilizado para outra finalidade, caso contrário, ficará sujeito à ação de intempéries que poderão provocar outros danos, como por exemplo, erosões.

$\mathrm{O}$ desmatamento de áreas de nascentes foi intenso na cidade, ocasionando vários problemas, tais como: erosões, assoreamentos, inundações, entre outros. Particularmente crítico, considera-se as áreas de cabeceiras de drenagem do Rio Monjolinho e do Córrego do Gregório, pois são áreas ainda com ocupação predominantemente rural, mas aonde a pressão da ocupação urbana vem se ampliando rapidamente. Além da proteção das nascentes, que é regulamentada por lei, o poder público deveria instituir leis de parcelamento do solo urbano nesta região que privilegiassem a infiltração das águas pluviais. A região é área de ocorrência de materiais arenosos com alta capacidade de infiltração, o que poderia reduzir os sérios problemas de inundações que a cidade vem sofrendo nas regiões centrais. Se estas áreas forem ocupadas sem estes cuidados, as obras contra enchentes, recentemente realizadas na re- 
gião central, perderão o efeito rapidamente e os problemas serão agravados.

CONCLUSÃO A técnica adotada neste trabalho mostrou-se bastante eficiente, pois fez uso de toda informação já disponível na área, agregando novos dados e, principalmente, sistematizando o conhecimento existente em um Sistema de Informações Geográficas associado a um banco de dados. Este procedimento, com certeza, permite disponibilizar para a administração pública da cidade e para os órgãos ambientais uma ampla gama de informações, de rápida consulta e que deve subsidiar os processos de tomada de decisão. Além disso, o levantamento realizado reflete o estado atual das degradações ambientais na área estudada, o que pode servir de documento para viabilizar futuras comparações e até para a atuação do ministério público. Em complementação, o sistema permite fácil atualização e agregação de novas informações, tendo sido desenvolvido em um SIG de domínio público, ou seja, acessível a todos.

Agradecimentos À FAPESP pelo apoio financeiro e à CAPES pela bolsa de estudo.

\section{Referências}

Aguiar R.L. 1989. Mapeamento geotécnico da área de expansão urbana de São Carlos, SP. Dissertação de Mestrado, Departamento de Geotecnia, Escola de Engenharia de São Carlos, Universidade de São Paulo, 2v.

Bortolucci A.A. 1983. Caracterização geológico-geotécnica da região urbana de São Carlos - SP, a partir de sondagens de simples reconhecimento. Dissertação de Mestrado, Departamento de Geotecnia, Escola de Engenharia de São Carlos, Universidade de São Paulo, 67p.

BRASIL. 2006. Presidência da República Federativa do Brasil, Casa Civil, Subchefia para Assuntos Jurídicos, Códigos - Código Florestal - Lei No 7.803, de 18 de Julho de 1989. Disponível em http://www.planalto.gov.br/ ccivil_03/Leis/L7803.htm. Consultado em 20/01/2006.

Rodrigues M. 1993. Geoprocessamento: um retrato atual. Revista Fator GIS, 1(2):20-23.

Feng J., Wang T., Qi S., Xie C. 2005. Land degradation in the source region of the Yellow River, northeast QinghaiXizang Plateau: classification and evaluation. Environmental Geology, 47:459-466.

Muro M.D. 2000. Carta de zoneamento para seleção de áreas frente à instalação de aterros sanitários no município de São Carlos - SP - escala 1:50.000. Dissertação de Mestrado, Departamento de Geotecnia, Escola de Engenharia de São Carlos, Universidade de São Paulo, 2v.

Nishiyama L. 1989. Mapeamento geotécnico preliminar da quadricula de São Carlos - SP. Dissertação de Mestrado, Departamento de Geotecnia, Escola de Engenharia de São Carlos, Universidade de São Paulo, 2v.
Pons N.A.D. 2006. Levantamento e diagnóstico geológicogeotécnico de áreas degradadas na cidade de São Carlos - SP, com o auxílio de geoprocessamento. Tese de Doutorado, Departamento de Geotecnia, Escola de Engenharia de São Carlos, Universidade de São Paulo. 2v.

Oliveira C.H. 1996. Planejamento ambiental na Cidade de São Carlos (SP) com ênfase nas áreas públicas e áreas verdes: diagnóstico e propostas. Dissertação de Mestrado, Ecologia e Recursos Naturais, Universidade Federal de São Carlos.

Câmara G., Souza R.C.M., Freitas U.M., Garrido J. 1996. Spring: Integrating remote sensing and GIS by object-oriented data modelling. Computers \& Graphics, 20:(3):395-403.

Zuquette L.V. 1981. Mapeamento geotécnico preliminar na região de São Carlos. Dissertação de Mestrado, Departamento de Geotecnia. Departamento de Geotecnia, Escola de Engenharia de São Carlos, Universidade de São Paulo.

Zuquette L.V. 1987. Análise crítica da cartografia geotécnica e proposta metodológica para condições brasileiras. Tese de Doutorado, Departamento de Geotecnia, Escola de Engenharia de São Carlos, Universidade de São Pau$10,3 \mathrm{v}$.

Manuscrito ID 9110

Submetido em 18 de setembro de 2007 Aceito em 23 de junho de 2008 Sistema eletrônico de submissão 